\title{
FORMAÇÃO DE PROFESSORES A DISTANCIA E EM SERVIÇO ATRAVÉS DE AMBIENTES DIGITAIS - A VIVÊNCIA DO PROINESP
}

\author{
Lucila M. Costi Santarosa ${ }^{1}$ \\ Liliana Maria Passerino \\ Mára Lúcia Carneiro ${ }^{3}$ \\ Marlise Geller ${ }^{4}$
}

\begin{abstract}
Resumo: Este artigo apresenta uma experiência de formação em serviço de professores, em Informática na Educação Especial, utilizando o ambiente digital de formação a distância-TelEduc. A experiência realizada pela UFRGS-CINTED-NIEE integra ações do Projeto Nacional de Informática na Educação Especial - PROINESP - da Secretaria de Educação Especial do MEC, envolvendo 310 professores, 164 escolas inclusivas e Instituições não governamentais localizadas em municípios da maioria dos estados brasileiros, distribuídos em 15 turmas. Destacam-se os aspectos positivos da experiência, bem como as dificuldades inerentes a implantação de processos inovadores.
\end{abstract}

Palavras Chave: Formação de professores; Educação a Distancia; Ambientes Digitais; Informática na Educação Especial

Abstract: This article presents a teaching service course experience - Informatics for Special Education - through the digital medium-based distance learning - TelEduc. The experience, carried out by UFRGS-CINTED-NIEE, is a part of the Projeto Nacional de Informática na Educação Especial (National Informatics on Special Education Project) PROINESP of the Special Education Council of MEC (Ministry of Education). 15 classes participated in it, totalizing 310 teachers and 164 inclusive schools and nongovernmental organizations (NGO) from municipalties situated in different Brazilian states. Positive aspects of the experience, as well as the difficulties of the implementation of inovative processes, are focused.

Keywords: Teaching Service Course; Distance Education; Virtual Learning Environments; Informatics on Special Education

\section{Introdução}

As Tecnologias de Informação e Comunicação (TICs) vêm causando um impacto significativo no processo de ensino e aprendizagem, apresentando novas perspectivas de acesso ao conhecimento e possibilitando outras maneiras de produzi-los através da constituição de redes de comunicação. $\mathrm{O}$ acesso à tecnologia expandiu $\mathrm{o}$ espaço da sala de aula para além de suas paredes físicas, levando professores e alunos a mergulharem em novos conhecimentos bem mais diversificados e atualizados, ao mesmo tempo em que auxiliou a superação de outras barreiras que afastam o aluno do acesso à educação, proporcionando o letramento e a inclusão digital.

Estudos e investigações, em âmbito nacional e internacional, vêm revelando a importância e o potencial que as TICs assumem no campo da Educação Especial. Temse observado que a utilização pedagógica dessas tecnologias vem produzindo melhores

\footnotetext{
1 Doutora em Ciências Humanas-Educação; Professora do PGIE e PPGEDU/UFRGS, Pesquisadora Senior do CNPq-MCT, Coord. Pedagógica do Proinesp2005, Coordenadora do NIEE-UFRGS. E-mail: lucila.santarosa@ufrgs.br

${ }^{2}$ Doutora em Informática na Educação e docente na Feevale da Licenciatura em Computação. E-mail: liliana@feevale.br

${ }^{3}$ Doutora em Informática na Educação. Coordenadora de Educação a Distância e docente na UERGS. Email:mara@uergs.edu.br

${ }^{4}$ Doutora em Informática na Educação e docente na ULBRA. E-mail: m.geller@terra.com.br V.3 No 2, Novembro, 2005
} 
efeitos na Educação Especial quando comparada à Educação de modo geral. Também se tem verificado que grande parte do que é planejado/aplicado a pessoas com necessidades educacionais especiais, principalmente na área de software, resulta em benefícios a outros usuários, estendendo-se seu uso de modo generalizado.

Ações mobilizando a preparação de professores utilizando ambientes digitais de formação a distância e em serviço vêm sendo realizadas no Brasil desde 1999 buscando atender, as metas do MEC.

A Educação a Distância, explorando ambientes digitais de formação de professores e profissionais, vêm se consolidando no mundo inteiro, seguindo variados modelos, com diferenciadas concepções teóricas. Na Formação de Professores, a Educação a Distância (EAD) tem uma função não somente pedagógica, mas social, considerando a necessidade existente de formação, principalmente no contexto nacional.

Utilizar ambientes digitais de formação a distância em um país nas dimensões do Brasil e com a complexidade que lhe é inerente, torna-se uma necessidade premente. Por outro lado, pensar em educação a distância sem uso da Internet, que oferece todo um potencial de interatividade, tão buscado e almejado em feitos anteriores, seria permanecer em paradigmas conservadores, que seguramente viriam resultar nos mesmos produtos ineficientes e insuficientes, até então alcançados, sujeitos às críticas relacionadas a custo-benefício e a modelos deficitários do ponto de vista do "isolamento interativo".

Além do mais, em uma sociedade tecnológica como a que vivemos, se faz necessária a apropriação dessas tecnologias por parte dos professores, além de colocálas à serviço da Educação, em especial da EAD, com qualidade, senão superior, pelo menos em níveis similares à educação em instituições de ensino (presencial).

A busca de alternativas metodológicas para a criação de ambientes digitais de formação de professores a distância, para atender a demanda nacional, vem sendo meta do governo nos últimos anos, principalmente no contexto das políticas do Ministério da Educação. Focalizando a área da formação de professores da Educação Especial, o MEC, através da Secretaria de Educação Especial, criou um Projeto Nacional de Informática na Educação Especial - PROINESP (SEESP, 2005)

O PROINESP visa incentivar o uso pedagógico das Tecnologias da Informação e Comunicação na Educação pelos alunos com necessidades educacionais especiais, por meio da disponibilização de recursos tecnológicos e, concomitantemente, da qualificação de professores. Assim, o programa tem como um dos seus objetivos principais a formação de professores de Instituições e Escolas públicas Inclusivas, para aplicações pedagógicas e de acessibilidade das TICs a PNEEs - visando a sua inclusão digital e social. O projeto foi criado por Santarosa (1997) com base nas recomendações do documento da Conferência Mundial sobre Necessidades Educativas Especiais (UNESCO, 1994) onde o acesso e qualidade ficam claros no texto que trata das novas idéias sobre necessidades educativas especiais, o "fomentar a integração e de lutar contra a exclusão"... "no desenvolvimento de estratégias que possibilitem uma autêntica igualdade de oportunidades" (fl. 23)... "criação de centros com bons recursos e equipamentos, aos quais as escolas pudessem recorrer e servir a maioria de crianças e jovens" (fl. 24).... "planos nacionais, regionais e locais, inspirados na vontade política e popular de alcançar a educação para todos” (fl. 25).

Também fica claro no texto do documento que refere às diretrizes de ação no Plano Nacional "o princípio de igualdade de oportunidade de crianças, jovens $e$ adultos com deficiências, no ensino primário, secundário e superior” (fl. 29), bem como aspectos de flexibilização no uso de ajudas técnicas e "pesquisas regionais $e$ nacionais devem ser desenvolvidas para a elaboração de tecnologia de apoio apropriado às necessidades educativas especiais" (fl. 34) ... "serviços educativos

\footnotetext{
$2 \longrightarrow$ V. $3 \mathrm{~N}^{\circ}$ 2, Novembro, 2005
} 
especiais deverão ser integrados nos programas de pesquisa e desenvolvimento de instituições de pesquisa" (fl. 36).

Com esse referencial o curso foi estruturado buscando alcançar os seguintes objetivos:

- formar em serviço, via Internet, os professores de escolas públicas inclusivas municipais e estaduais e de entidades de educação especial no uso pedagógico das Tecnologias da Informação e da Comunicação e da acessibilidade com vistas ao desenvolvimento e à inclusão social de PNEEs;

- auxiliar os professores na implantação, nas respectivas instituições, de atividades de uso das Tecnologias da Informação e da Comunicação, integradas às atividades curriculares que desenvolvem, junto aos seus alunos especiais.

Conforme já salientamos, orientar a formação de professores de forma tal que integre a teoria a sua práxis é um ponto inquestionável (SANTAROSA e outros, 2001). Fornecer um modelo de formação continuada que contemple a questão da inclusão e do uso das novas tecnologias no processo educativo é, sem dúvida, um dos objetivos mais importantes do presente projeto (PROINESP), utilizando para isto um ambiente digital de formação a distância que permita, ao mesmo tempo, vivenciar o uso das tecnologias e propiciar um espaço para as trocas de experiência e para a construção cooperativa/colaborativa de conhecimento.

Nesse contexto, em cursos a distância e em serviço o PROINESP vem desenvolvendo suas ações, das quais destacamos em 2000 - 38 laboratórios interligados em rede com 494 computadores, formando-se 160 professores e em 2001 - 96 laboratórios interligados em rede com aproximadamente 1000 computadores, formandose 496 professores, em todo o país. Atualmente, o PROINESP vem formando 310 professores de 164 escolas inclusivas e Instituições não governamentais, distribuídos em 15 turmas, com 15 formadores , 30 monitores, 9 conferencistas e uma equipe de técnicos especializados. Podemos observar na Figura 1 a distribuição das Instituições e Escola Inclusivas que estão fazendo parte do curso atual.
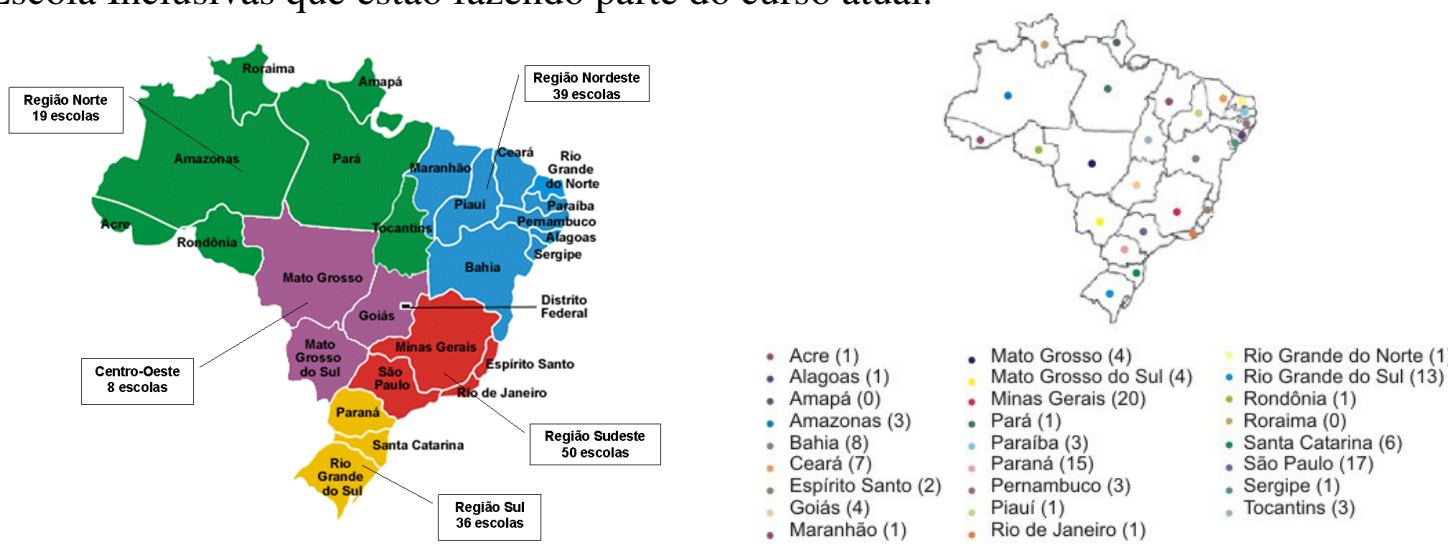

Figura 1 - Instituições e Escolas atendidas pelo Proinesp2005

\section{Ambiente Digital de Formação a Distância: Estrutura do curso}

O curso de formação de professores a distância e em serviço, tev3 a duração de 120 horas, das quais 20 h são de caráter presencial, pois envolveu conteúdos de prérequisitos que visavam preparar o professor para o seu ingresso no curso. As demais 100 horas integraram sete disciplinas, distribuídas ao longo de 15 semanas, intercaladas com conferências pela Internet, envolvendo uma riqueza de atividades e 
de materiais, que buscaram cobrir, de formas alternativas e diversificadas, os conteúdos explorados em cada uma das seguintes disciplinas:

1. Conhecendo o ambiente do curso (TelEduc): Apresentação e exploração dos recursos e ferramentas do ambiente TelEduc, através de atividades orientadas.

2. Tecnologias Assistivas: Apresentação, exploração, observação e manuseio de diferentes dispositivos e interfaces de hardware e software que possibilitam o acesso aos recursos de ambientes computacionais para pessoas com necessidades educacionais especiais. Informações e orientações que devem ser seguidas no processo de interação de PNEEs com os recursos dos ambientes digitais.

3. Usos pedagógicos da Internet: Estudo e utilização de diversos recursos da Internet que suportam a interação e comunicação via ambientes digitais virtuais. Exploração de ambientes de Navegação, do correio eletrônico e produção/publicação de páginas Web. Reflexão sobre os usos pedagógicos desses recursos e utilização/observação com os alunos especiais.

4. Acessibilidade: Estudo de critérios e requisitos para promover o acesso a ambientes telemáticos de pessoas com necessidades educacionais especiais. Informações sobre as recomendações que devem ser seguidas na construção de páginas Web, possibilitando o seu acesso por PNEEs. Observação e utilização de sistemas que avaliam e validam a acessibilidade de páginas WEB.

5. Ambiente Logo: Estudo da filosofia e linguagem LOGO. Exploração e utilização de comandos da linguagem do ambiente Logo. Construção de projeto(s) envolvendo o Logo. Observação e relato do desenvolvimento de projetos com o Logo pelos alunos especiais.

6. Softwares educacionais: Estudo sobre ambientes digitais de aprendizagem (software). Análise e avaliação de softwares do ponto de vista do seu potencial educacional. Utilização e reflexão sobre o uso de softwares educacionais com aluno com necessidades educacionais especiais.

7. Plano de ação pedagógica para a instituição: Analisar e avaliar a pertinência/relevância do uso de recursos computacionais na construção do Plano de Ação Pedagógica. Reflexão a partir dos conhecimentos e experiências vivenciados, ao longo do curso, para a elaboração de um Plano de Ação Pedagógica. Socialização do Plano de Ação Pedagógica, através de sua divulgação em ambientes virtuais.

Palestras Via Internet : As palestras, transmitidas via Internet, visam trabalhar conteúdos específicos relacionados às diferenciadas síndromes/deficiências. Essas atividades têm como propósito suprir, principalmente, os professores que não tem formação na área de Educação Especial. Assim, vários especialistas convidados trabalham essas áreas de conhecimento, fundamentais para toda a dinâmica do trabalho dos professores, junto aos alunos com necessidades educacionais especiais, essencialmente no que se refere aos conteúdos das disciplinas e suas aplicações à pratica pedagógica.

As conferências envolveram os seguintes temas: Inclusão escolar: quais sentidos?; Tecnologias Assistivas para Deficientes Visuais; A Inclusão de Deficientes Visuais na Rede de Ensino; Síndrome de Down: aspectos da síndrome, do desenvolvimento e da educação escolar; Deficiência Auditiva ou Surdez?; Acessibilidade e Tecnologias Assistivas; $O$ Espectro do Autismo; $A$ Neuropsicopedagogia e a Paralisia Cerebral; Paralisia Cerebral: possibilidades na aprendizagem escolar.

Ambiente digital de formação a Distância: Metodologia do curso 
Destacamos a experiência mais recente, através do curso PROINESP, que envolveu, em cada uma das 15 turmas, um formador e dois monitores.

Essa equipe de formadores/monitores favorece um processo de interação/comunicação permanente, possibilitando um acompanhamento constante dos trabalhos dos professores e atendimento a suas dúvidas, fazendo com que os professores se sentissem sempre apoiados ao longo do curso em seu processo de desenvolvimento e construção de conhecimento.

Cada uma das escolas/instituições participante, teve dois professores realizando o curso e desenvolvendo atividades em conjunto. Nas instituições que possuiam professores cegos realizando o curso, o grupo foi composto de três professores, sendo, pelo menos, um vidente Esse processo favoreceu a construção/reflexão conjunta de atividades de interesse de cada escola/instituição, visando atender à diversidade e peculiaridades de cada uma.

Em cada disciplina o professor, ao apropriar-se da tecnologia, desenvolveu atividades junto aos seus alunos e relatou ao grupo, para discussão/reflexão sobre as mesmas. Dessa forma, esse procedimento fez com que o professor atuasse de forma imediata sobre sua comunidade de alunos, podendo observar e discutir suas vivências com seus pares e formadores, em um processo de ação/reflexão/depuração na construção do conhecimento.

Como ambiente virtual de apoio ao curso, foi escolhido o TelEduc que se constitui em um ambiente para a criação, participação e administração de cursos na Web, criado e mantido pelo Nied/Unicamp.

O TelEduc permite a personalização da sala de aula virtual, através da escolha de todas ou apenas um subconjunto das ferramentas oferecidas pelo ambiente, durante todo o curso ou dinamicamente mudando de acordo com a metodologia do formador (professor).

O curso foi organizado através de Agendas semanais, apresentando as principais orientações sobre o trabalho. A esta Agenda, foram associadas uma série de Atividades, apoiadas por Materiais de Apoio e Leituras (SANTAROSA e outros, 2001).

Os Fóruns de Discussão foram utilizados intensamente como espaço de aprofundamento das discussões, enquanto encontros regulares via bate-papo permitiam o esclarecimento de dúvidas e debates em tempo real.

$\mathrm{O}$ ambiente ainda proporcionou recursos para o professor acompanhar o processo de aprendizagem dos alunos, que publicavam suas produções no Portfólio Individual ou no Portfólio de seu Grupo e registravam sua caminhada e autoavaliação constante no Diário de Bordo.

O Perfil ofereceu um espaço para o usuário apresentar uma série de informações pessoais e profissionais e, se desejasse, poderia enviar sua fotografia. Estas informações podiam ser consultadas pelos demais usuários do ambiente, propiciando mais um recurso para a aproximação dos participantes através da identificação de interesses comuns. A idéia desse recurso foi, em princípio, fornecer um mecanismo para que os participantes pudessem se conhecer e desencadear ações de comprometimento como grupo, abrindo caminho para a escolha de parceiros para desenvolver as atividades do curso.

Assim, os vários recursos do ambiente foram explorados para atender a essa dinâmica do curso. O uso intenso do Portfólio, como espaço de publicação das produções dos professores e acompanhamento pelos formadores/monitores, bem como o Diário de Bordo utilizado para auto-avaliação, oportunizaram um espaço de construção e reflexão por parte dos professores.

O correio eletrônico foi a ferramenta de comunicação usada de forma mais intensa e direta entre os formadores/monitores e professores e entre professores. Pelo 
menos uma vez por semana os formadores/monitores reuniam-se com os alunos através do bate-papo, propiciando um momento de interação mais significativo. Foram incentivadas as trocas de mensagens entre os professores e alunos das diferentes Instituições/escolas.

As conferências pela Internet permaneceram disponíveis durante uma semana para os professores assistirem e discutirem sobre o tema através de Fóruns e Bate-papos específicos para cada assunto tratado. A partir dessas discussões foram levantadas as questões, dúvidas e sugestões dos professores para a organização de um FAQ (Frequent Asked Questions), que ficou disponível no ambiente do curso.

Ao término das disciplinas, os professores tiveram um espaço para divulgar uma proposta pedagógica para sua escola/instituição, utilizando/explorando os conhecimentos construídos ao longo do curso. Tal proposta está disponível e socializada a todos os componentes do curso através do portal do Curso, ficando um espaço aberto para o professor continuar atualizando as suas realizações posteriores ao curso.

\title{
A vivência do Proinesp analisada
}

A análise da experiência possibilitou ressaltar alguns aspectos positivos em relação ao curso e a participação dos professores em formação, trazendo alguns depoimentos espontâneos dos próprios professores como agentes do processo. Assim, destacamos alguns registros que atestam esses aspectos:

- eles aprenderamm a superar dificuldades, pois a participação em um curso a distância exige um maior grau de autonomia e disciplina. Podemos verificar esta atitude nos depoimentos a seguir:

\begin{abstract}
No início do curso somos cercadas pela ansiedade e curiosidade acerca do desconhecido. Ficamos indagando: como será? como me sairei? o que vou acrescentar? o que vou aprender? São tantos questionamentos...tantas dúvidas...tanta coisa nova a aprender....e ainda temos um fator muito importante e cruel: o tempo...Ainda temos que administrar nosso tempo...tão precioso, tão requisitado...Mas tenho certeza que conseguiremos! Somos fortes e determinadas.
\end{abstract}

Obstáculos existem para serem vencidos,com vontade de adquirir novos conhecimentos e descobertas de como trabalhar e ajudar nossos alunos é que se torna muito gratificante.Baixar alguns arquivos foram as minhas dificuldades desta semana, acho que incomodei bastante os formadores,mas foi por uma boa causa.A cada semana é uma descoberta nova e necessária para o meu desenvolvimento e o meu desempenho nesta $3^{a}$ semana.

- sentiram-se parte de algo maior, ao perceberem a influência de seu trabalho sobre os seus alunos e o compartilhamento de experiências com os colegas de todo o país, conforme exemplificamos nos seguintes depoimentos:

Iniciaram os preparativos para a implantação do laboratório, tão esperado ao longo do ano, finalmente o sonho torna-se realidade. Estamos muito felizes com esta nova era que se inicia em nossa escola.

Tenho repensado minha prática pedagógica, não só na informática, mas como educadora, formadora e enfim tenho aprendido como é importante termos autonomia associada a responsabilidade. $O$ curso está sendo de muita valia,nos dá oportunidade de crescermos juntos, interagindo com todos,mesmo tão distantes geograficamente.

- reconheceram suas falhas (atraso na entrega dos trabalhos, dificuldades básicas no uso dos recursos de informática), mas esforçaram-se para buscar soluções. 
As experiências que vivenciamos com os alunos, foram gratificantes. $\mathrm{Na}$ mesma forma que nós ficamos perplexos eles também; pois isso é novo e rápido. Então há um feedback instantâneo. O desejo de estar interagindo foi enorme. Todos queriam criar. A nossa maior dificuldade é que só existe este contato na escola. Tivemos que estar pontuando... Acreditamos que as informações de alguns sites que visitamos com eles foram além, pois queriam fazer muitas coisas ao mesmo tempo.

- no caso específico de alunos surdos e cegos, o esforço pareceu ser maior ainda, com o único objetivo de efetivamente participar, superando suas limitações;

Sou surdo, então você sabe informática, você vai pesquisar comigo, é difícil compreender os textos e pesquisas, porque eu vou escrever,pesquisar e trabalhar informática educacional. Mas preciso chamar as minhas amigas para corrigir os textos, por isso eu e elas estamos em constante comunicação de linguagem de sinais, fácil. Claro!!! .

Aprendi a construir juntos, conjugar o coletivo [...] gostei da experiência, talvez artesanal, de construir a página com todos os comandos manuais. Contei com uma disposição interna, uma motivação porque aprendi o que desejava aprender [...].Aprender é um verbo conjugado ad infinitum! "(professora cega)

- apoiaram-se uns nos outros, trabalhando em duplas na instituição e interagindo com os colegas no ambiente do curso;

Estamos estudando sobre inclusão/cooperação/interação. Vejo os formadores atenciosos e preocupados. Entre nós colegas acho que falta interação, estamos muito distantes. No bate papo que pude participar ouve mais diálogo entre formadores e alunos e alunos com alunos? (para pensarmos).Vamos interagir também?

Fico mais tranqüila em saber que não é só eu que estou com dificuldades, lendo alguns relatos de outros colegas me sinto um peixe fora d'água! Vamos em frente que a gente chega lá!

- aprofundaram conhecimentos e compartilharam com os colegas, divulgando suas produções e realizações no curso e em suas instituições;

Colegas e formadores leiam o mural a $S$. escreveu sobre uma atividade que foi realizada organizada pelos nossos alunos (maiores) juntamente com suas professoras que foi um sucesso.

- crescimento profissional e pessoal, pois perceberam que o curso efetivamente contribuiu com o seu trabalho nas instituições e escolas;

Em nossa Instituição temos um laboratório de Informática bem equipado. Há dois anos e meio comecei a trabalhar com as crianças, com recursos de CDs de histórias jogos dentre eles MICROMUNDOS, objetivando dar continuidade aos temas vividos na sala de aula com professores. Nenhum professor foi capacitado sobre as novas tecnologias para trabalhar com nossos alunos, que na verdade são muito comprometidos. Minha preocupação sempre foi neste caso com aqueles que tem dificuldade motora, cognitiva de estar até mesmo mais próximo deste recurso, pois todo conhecimento que estou adquirindo agora é bastante novo e distante da nova atuação até antes do curso. Com esses novos conhecimentos e práticas o Laboratório estará voltado para quem é de Direito.

O trabalho envolvendo o uso do correio eletrônico pelos alunos, foi e está sendo muito rico, os alunos sentiram-se valorizados, se deixar por conta deles acredito que todo dia eles querem estar no computador para ver suas mensagens. $O$ envolvimento e entusiasmo foi tanto que toda turma quer ter email. 
- tornaram-se professores reflexivos e críticos, analisando sua prática a partir dos subsídios teóricos e discussões propostos no curso;

Após ler o texto..., percebi que acertei em alguns aspectos e errei em outros aspectos, com relação à inclusão de um aluno de 14 anos com Síndrome de Down. Em uma turma da $4^{a}$ série do Ensino Fundamental, na qual eu era professora. Gostaria de saber se acertamos em colocar esse aluno na série mencionada, levando em consideração a sua idade cronológica, mesmo ele apresentando déficit na parte cognitiva? Na escrita, por exemplo, ele encontrava-se ainda escrevendo serrilhado, começando a empregar algumas letras na escrita do nome deles e nos demais conteúdos ele não demonstrava interesse no que estava sendo estudado pela turma. Aguardo resposta, pois fiquei muito tempo angustiada sem saber se agir corretamente.

- acreditaram que é possível mudar,incluir e aprender sem limitações, às vezes simplesmente por descobrir que isto é possível ;

Foi muito gratificante para mim ver meus dois irmãos DM, alunos da Escola Especial em que eu trabalho, um com quarenta e dois e outro com quarenta e quatro anos, fazendo uso da internet. Através do links propostos no site do NIEE, pude oferece-lhes jogos e brincadeiras que eles adoraram.

É maravilhoso está interagindo com todos vocês e juntos vencendo desafios e buscando a causa principal:aprender e ensinar simultaneamente.

positivos:

Cabe, ainda, salientar outras considerações dos professores como pontos

- $35 \%$ destacaram à proposição de uma reflexão e qualificação do trabalho digital e as atividades propostas aos alunos especiais, como uma nova maneira de pensar e interagir com os alunos PNEEs;

- $25 \%$ apontaram crescimento intelectual, pessoal e profissional, salientando a descoberta do recurso tecnológico como uma nova alternativa ao ensino tradicional, propiciando ao aluno a oportunidade de construir sua aprendizagem, demostrar seu potencial, aumentar sua auto-estima e melhorar o relacionamento inter e intrapessoal entre colegas e professores;

- $20 \%$ destacaram a possibilidade de integrar as tecnologias a todos os profissionais da instituição;

- $20 \%$ apontaram a abertura de concepções, oportunidades de aprendizagens e conhecimentos, troca de experiências através do contato com novas propostas, atividades e softwares, percebidos como agentes de mudanças na vida do sujeito considerado "diferente" para a sociedade como um todo, contribuindo tanto para inclusão social quanto digital desse cidadão.

Alguns aspectos negativos também foram destacados pois interferiram na participação e aproveitamento dos professores como alunos do curso. São exemplos disto:

- falta de estrutura física (recursos de hardware e acesso a internet), o que exigiu, do professor em formação, o seu deslocamento para outras instituições; o acesso somente com recursos de sua casa ou o uso de um único microcomputador disponível na sua instituição;

Devido as dificuldades de acesso a internet com meus alunos, visto que nossa escola não tem laboratório, atrasei minhas atividades, mas já programei para levá-los para a APAE e breve estarei compartilhando minha experiência com todos. 
- falta de preparação para participar de um curso a distância, aliada a falta de experiência no manuseio de tecnologia, pois a grande maioria dos professores era iniciante no uso dos recursos de informática.

\begin{abstract}
No nosso laboratório estamos precisando o mais rápido possível de pessoas que tenha interesse de ver realmente as coisas mudarem e não apenas fazerem de conta, pois no momento estamos todos sem saber como fazer para enfrentarmos este curso que é de grande importância para nós que estamos do lado dos excluídos, vendo que nosso laboratório está indo de água abaixo: computadores precisando de manutenção, equipamentos, etc.
\end{abstract}

- insegurança e problemas de auto-confiança, demonstradas na preocupação em publicar os trabalhos sempre corretos e sem erros, pois estaria expondo suas dificuldades perante os colegas:

\begin{abstract}
hoje ainda estou com o resultado que alcancei, depois de tantas horas na frente do computador. Nesta 5 semana, mudei de estratégia, fiz o certo li atentamente todas as atividades, fiz anotações em um caderno só para o curso, só hoje vou enviar. Espero alcançar os objetivos das atividades. Quanto a interação, (falo por mim), talvez seja a preocupação de estar certolerrado, o nosso desempenho, e se expor aos colegas de maneira errada. A interação vai acontecer com o passar das semanas. Leio os relatos de todos, mas não coloco nada, no bate papo já no final passei uma mensagem para uma colega, mas não tive respostas acredito que foi no momento que ela estava se retirando da sala.
\end{abstract}

\title{
Considerações Finais
}

As considerações feitas pelos professores-alunos do curso possibilitam refletir sobre o potencial das tecnologias na formação de profissionais a distância, tendo presente as dimensões de um país como o nosso, destacando-se esse recurso tecnológico como um forte aliado para a solução de muitos problemas criados pelas desigualdades, distâncias, condições econômicas e sociais, que fazem parte desse cenário multicultural nacional.

Poder partilhar problemas comuns, buscando soluções conjuntas, permeadas por trocas em vivências e experiências diferenciadas, sejam elas individuais e coletivas, trazem uma riqueza impar em termos de crescimento profissional e consciência de uma realidade que se vivencia no dia a dia, a qual fazem parte da estrutura de nosso sistema de ensino, principalmente, destacando-se a Educação Especial. Logicamente, existem barreiras a serem superadas para poder-se atingir a todos professores-alunos de um curso como esse. Muitas das escolas hoje se encontram em cidades distantes dos grandes centros e com dificuldades de acesso à Internet. Em muitas delas, o acesso à Internet é restrito ao computador disponível na secretaria. Assim, a idéia de "formação em serviço", que implica na realização das atividades do curso com os alunos especiais da escola/instituição, torna-se muito difícil ou inviável de ser implementada.

Também um aspecto a ser destacado é a própria cultura que envolve a implantação e participação de cursos a distância, já que a relação de tempo e espaço altera-se de forma drástica. Como aceitar que estando em um bate-papo na Internet, o professor está em aula? Nesse sentido, vários professores relataram dificuldades em participar dessas atividades, por não estarem liberados de suas atribuições regulares da escola/instituição. Em nosso contexto no qual predomina a formação presencial, a alteração para a formação não presencial carrega o ônus inerente a todos os processos de mudança e inovação. Enfrentar as resistências e abrir-se para o novo e para alternativas diferenciadas das usuais, tende a ser um processo de difícil assimilação e mais lento do que o desejado. 
Na medida em que o professor se engaja nesse processo, observa-se uma maior valorização que envolve vários aspectos, como alguns já apontados, e apresenta um saldo positivo da experiência em desenvolvimento. Nesse particular, destacamos que a atividade com os alunos especiais, principalmente aquelas que envolvem a comunicação via Internet, está tendo grande repercussão no grupo, bem como a vivência de criar e publicar páginas na Web, pois instigou também os participantes a divulgarem e compartilharem suas experiências com o grupo e com o mundo.

Também não podemos deixar de salientar que os recursos de interação assíncrona, mas principalmente síncrona (bate-papo), são fundamentais para os professores sentirem-se próximos a seus pares e com os formadores/monitores, como uma metáfora de "presença real de sala de aula", onde cada um pode expressar o que sente e "ouvir" o outro. Acreditamos que tais recursos estão sendo os grandes aliados para a permanência e o sentimento gratificante de professores-alunos nos cursos EAD.

Acreditamos ainda que esses novos caminhos para formação de professores e para inclusão digital/social de PNEEs poderão trazer respostas, para além de circunscrever-se unicamente em nosso país, a problemas sem solução com os recursos, meio e formas utilizados até o momento. Nossa expectativa é de que os recursos tecnológicos, com todo seu potencial, sejam fortes parceiros para a solução desses problemas que circundam e persistem na Educação Especial.

\section{Referências Bibliográficas}

ROCHA, H. Introdução ao TelEduc. NIED/UNICAMP, 2001. Disponível na Internet: http://hera.nied.unicamp.br/teleduc.

SANTAROSA,L.M.C. Projeto Nacional de Informática na Educação Especial. SEESP-MEC.1997 (Projeto inicial apresentado, como consultora, a SEESPMEC)

SANTAROSA, L.M.C; PASSERINO, L. ; CARNEIRO, M. L. F. ; GELLER, M. E. Formação de professores a Distancia e em serviço: Ambiente TelEduc no Projeto Nacional de Informática na Educação Especial do MEC. Revista de Informática na Educação: Teoria e Prática - PGIE. v.4 n 2 -37-48 - dez 2001

SEESP-MEC. Ações da SEESP: Capacitação de Recursos Humanos. Disponível na Internet: http://www.mec.gov.br/seesp/capacita.shtm

UNESCO. Declaração de Salamanca e Linhas de Ação sobre Necessidades Educativas Especiais. CORDE. Brasília, 1994. 